\title{
İş Yeri Adlarının Dil- Kültür Zemininde İncelenmesi: Develi İlçesi Örneği
}

DOI: $10.26466 /$ opus.703795

*

\author{
Melike Somuncu * \\ * Siirt University \\ E-Posta: $\underline{\text { melike.somuncu@siirt.edu.tr }}$ \\ ORCID: $\underline{0000-0002-9101-3012}$ \\ Öz
}

Dil anlaşmayı sağlayan bir araç olup yeryüzündeki insanların duygu ve düşüncelerini ifade etmede önemli bir konumdadır. Toplum, dil ile var olmaktadır ve kültürün yansıtıcısıdır. Bu yansıtma çerçevesinde iş yerlerine verilen adlar da önemli bir konuma sahip olmuştur. İs yerlerine yabancı dilde ad verme eğilimi işletme sahiplerini etkisi altına alan yeni bir akımdır. Bu yeni akımın doğmasında toplumsal yapıya özgü kontrol altına alınamayan değişkenler etkilidir. Bu çalışma üç bölümden oluşmuştur. Birinci bölümde dil ile kültür arasındaki ilişki irdelenmiştir. İkinci bölümde iş yeri isimlerinin dile etkilerinden bahsedilmiştir. Ayrıca şimdiye kadar yapılan iş yeri isimleri ile ilgili çalışmalar da zikredilerek bu çalışmaların vardığg ortak noktadan bahsedilmiştir. Üçüncü bölümde ise küçük bir ilçe olan Develi'deki işletme sahiplerinin iş yerlerine isim verirken nasıl bir yol izledikleri incelenmiştir. Incelenen iş yerleri isimleri hem dil hem kültür bağlamında ele alınmıştır. Çalışmada dilde kirliliğe yol açan nedenlerin Develi iş yerleri isimlerine yansıyıp yansımadı̆̆ı dil ve kültür zemininde analiz edilmiştir.

Anahtar Kelimeler: Develi, iş yeri adlarl, dil, kültür 


\title{
Analysis Of Workplace Names On Language - Culture: Example Of Develi District
}

\begin{abstract}
Language is an instrument that provides agreement, and it has an important position in expressing the feelings and thoughts of the people on earth. Society exists with language and reflects culture. Within the framework of this reflection, the names given to the workplaces also have an important position. The tendency to name businesses in a foreign language has been a new trend that has affected business owners. Variables that cannot be controlled under social structure are effective in the emergence of this trend. This study consists of three parts. In the first part, the relationship between language and culture is examined. In the second part, the effects of workplace names on language are mentioned. In addition, studies related to workplace names made up to now have been mentioned and the common point of these studies has been mentioned. In the third part, the way in which the business owners in Develi, a small district, gave their names to their workplaces, was examined by the compilation method. The names of the workplaces examined are dealt with in the context of both language and culture. In the study, it was analyzed on the language and culture ground whether the causes of language pollution reflected on the names of Develi workplaces.
\end{abstract}

Keywords: Develi, workplace names, language, culture 


\section{Giriş}

\section{Dil-Kültür İlişkisi}

Dil, "insanların düşündüklerini ve duydukların bildirmek için kelimelerle veya işaretlerle yaptıkları anlaşma, lisan, zeban." (TDK, 2019) olarak tanımlanmaktadır. Sistematik olarak dil, göstergeler dizgesi olup, dizge içindeki her göstergenin dış dünyaya işaret ettiği bir alana sahiptir. Dil için bir dış dünya gerçekliği bulunur ve bu gönderme alanı kültür ile ilişkilidir (Asutay, 2007). Anlaşmayı sağlayan dil, insanın dünyadaki yerini ve değerini belirlemektedir. "Konuşma yeteneği, dolayısıyla dil, insanı insan yapan niteliklerin başında gelir. Onun duyguların, düşüncelerini, isteklerini bütün incelikleriyle açığa vurmasına, yaşamını sürdürebilmesine olanak sağlar." (Aksan, 2015). Yaşamın her noktasında bulunan dil, toplumdan bağımsız değildir. “İnsanın varlığı dil ile mümkün olduğu gibi, toplumların varlığı da ancak dil ile mümkün olmaktadır. Dil yoksa toplum da yoktur. Dil, bir toplumun kültür kimliğidir" (Ünalan, 2005, s.14). Bu kimlik insanların duygu ve düşüncelerini, hayata bakış açısını, yaşam biçimini aktarmaya olanak sağlamaktadır.

Gökalp’a göre kültür, “Bir milletin dinî, ahlakî, aklî, estetik, lisani, iktisadî ve fennî hayatlarının ahenkli bir bütünüdür" (Gökalp, 1975, s.27). Bu bütünlük içerisinde kültür var olur. Var oluş serüveninde kültür, toplumların aynası işlevini üstlenmektedir. "Kültür sözcügü dört anlamda kullanılmaktadır: Bilim alanında uygarlık; beşeri alanda eğitim sürecinin ürünü; estetik alanda güzel sanatlar ve maddi (teknolojik) ve biyolojik alanda üreme, tarım, ekin, çoğaltma ve yetiştirme" (Güvenç, 1994, s.96). Kültürün en önemli vasfı öğrenilir olmasıdır. Tarihî, sürekli, toplumsal olması da kültürün diğer önemli özelliklerindendir. Kültür, idealleştirilmiş kurallar sistemine sahip olup ihtiyaçları karşılayıcı, doyum sağlayıcı, bütünleştiricidir (Güvenç, 1994, s.101-104). Bir milletin asırlar boyunca oluşturduğu yaşam tarzlarının kodlarını barındıran hafıza işlevi gören kültür, milletlerin algı, tutum ve davranışlarıyla oluşan yaşam biçimi, maddi ve manevi değerler toplamıdır. Bu değerler nesilden nesile aktarılmaktadır (Göçer, 2012, s.50). Değerlerin nesilden nesile aktarılmasının en önemli nedeni insanoğlunun kimlik arayışında millet olarak var oluş serüvenlerini sürdürebilmeleri için millî bir kültüre ihtiyaç duymalarıdır. 
Dil bir kültürün gelişip güçlenmesinde, nesilden nesile aktarılmasında önemli bir göreve sahiptir (Güleryüz, 2004, s.124). Bu yüzden kültür denilen maddi ve manevî değerler bütününün öğrenilmesinde baş araç dildir (Devrim, 2004, s.131). "Kültürü değişen bir toplumun dili, düşüncesi, töresi, göreneği de değişir" (Akarsu, 1998, s.88-89). Bu yüzden Humboldt'un "ulusun dili ruhudur; ruhu da dili" (Aksan, 2009, s.42) demesi kültürün bir parçası olan dilin, bir milletin en önemli değeri olduğunu kantlar niteliktedir.

Dil, toplumları millet hâline getirir. Fakat insanlar, küreselleşen dünyada daha huzurlu bir hayata sahip olmayı sağlayacak olan her projede bir bütünleşmeye gitse de, bir toplumun millet olmasını sağlayan her türlü duygu ve düşüncede tamamen dillerini muhafaza ve geliştirmeye ihtiyaç duyar (Karademir, 2004, s.1577). Bu ihtiyaç doğrultusunda dünya üzerinde konuşulan diller arasında tamamen saf bir dil var midır? sorusuna cevap olumsuz olacaktır. Milletler arası ilişkiler dikkate alınırsa yeryüzünde konuşulan bütün dillerin başka dillerden kelime aldığını, saf dil diye bir şeyin olmadığını söylemek mümkündür (Özkan ve Musa, 2004, s.96). Yalnız Turan, “Türk milleti tarih boyunca türlü din, medeniyet ve coğrafi saha değiştirmiştir. Bu durum Türkçenin de gelişmesine, mühim değişikliklere uğramasına sebep olmuştur. Bununla beraber Türk dili, bünyesindeki hayrete şayan kudret ve hayatiyet sayesinde mücadele ettiği dil ve kültürlere yalnız mukavemet etmemiş çok kere de zafer kazanmıştır" (Turan, 1980, s.191) diyerek Türk dilini ayrı bir kategoriye sokmakta ve Türk dilinin ve kültürünün daha katıksız olduğunu savunmaktadır. Bu düşünce günümüzde canlılığını nispeten korusa da iş yerlerine isim verilirken izlenen yolda katıksız veya özentisiz bir dil ve kültürle artık karşılaşılmadığını söylemek mümkündür. Çünkü kültür ile dil arasında sıkı bir ilişki vardır. Değişen yaşam tarzları kültüre yerleşmekte ve dolayısıyla dilde bazı değişimler meydana gelmektedir. Dilde değişim Türkçenin kurallarından ve yapısından uzak, Türkçeye kimi zaman aykırı olan kullanımlar olarak karşımızı çıkmaktadır. Dil-kültür bağlamında iş yerleri isimlerindeki en dikkat çekici hususiyet de budur.

\section{İş Yerlerine Verilen Adların Dile Etkisi}

İş yeri, üretici ve tüketici arasında önemli bir bağ kurma özelliğine sahip olan, tüketim mekânı, pazar ortamının da en önemli organıdır (Sancak vd., 2008, s.159). Herkesin ihtiyaçlarını karşıladığı mağazaların, iş yerlerinin ve diğer 
kurumların adları, bir yönüyle insanlara o mekândaki toplumsal iletişimin bir fotoğrafını sunmaktadır (Karademir, 2004, s.1577).

Pek çok işletme sahibi karşılaştıkları sorunlara geçici çözümler aramaktadırlar. Bu da zaman içinde kurum kimliğinde veya iş yeri isminde istenmeyen bir tortu oluşturabilmektedir (Soğanc1, 2002, s.11). Bu tortu dil kirliliğinin ta kendisidir. Dil kirliliği "girdiği dile yerleşerek o dilin ses ve yazım kurallarına uyan yerleşmiş ve yabancılığını devam ettiren yerleşmemiş yabancı sözcüklerin hızla yazılı ve sözlü dile girerek yaygınlaşması, kullanım sıklığının artması, Türkçe sözcükler yerine tercih edilmesi, kullanım ve kavram alanlarının Türkçe sözcükler aleyhine genişlemesi, eğitim-öğretim diline, yazılı ve görsel basına, reklam diline yerleşmesidir" (Küçük, 2007, s.505) şeklinde tanimlanabilir.

Dil olmazsa iletişim gerçekleşemez. Dil canlı bir varlık olduğu için yabancı dillerden etkilenmeye açı bir pozisyona sahiptir. Yalnız yabancı dillerden olan etkilenme dilde yozlaşmaya neden olabilmektedir. Yozlaşma "dilin yapı ve işleyişinde var olan yaratıc, güzelleştirici ve zenginleştirici öz ve özellikleri kaybetme doğrultusunda yol alarak, anlatım gücü bakımından gerileme sürecine girmiş olması" (Korkmaz, 1997, s.129)dır. Bir toplum dilini kaybederse kültürünü ve hatta kimliğini de kaybedebilir. Yalnız diller arasında katıksız bir dile rastlamak imkânsızdır. "Kültürler ve diller arası etkileşim sonucu yeryüzünde konuşulan tüm diller birbirlerinden kelime alışverişinde bulunmaktadır (Özkan ve Musa, 2004). Ama özenti ile kullanım sahasına sahip olan yabancı kelimeler Türk kültürünü sarsacak duruma gelmiştir (Akalın, 2002, s.49). Bir dil, hızla gelişen dünyada bilimsel, teknolojik, ekonomik vb. alandaki üretimlere kendi dilinde bir karşıllk geliştiremezse diğer dillerden sözcükler, cümleler almak zorunda kalmaktadır. Dil, yeterince araştırılıp geliştirilemezse diğer dillerin etkisine maruz kalmaya mahkumdur (Zengin, 2017, s.298). Toplum hayatında dil bilincinin çok da var olmadığının birçok göstergesi vardır. Bu göstergelerden biri de iş yerlerine verilen isimlerdir (Şeyda, 2005). İş yerlerine verilen isim, hem işletme sahibinin özel nedenlerle seçtiği hem de alıcıya en kısa yoldan en çok iletiyi ulaştırmayı amaçlayan dil göstergeleridir. (Sancak vd, 2008). İş yerlerine verilen isimlerde işletme sahibi hitap ettiği kitlenin kültürel yapısını da dikkate almak zorunda olduğu için bu isimler toplumun kültürünü yansitan önemli göstergelerden biri konumuna geçer (Şeyda, 2005, s.79). İş yerlerine yabancı dilde ad verme eğilimi 
işletme yöneticilerini etkisi altına alan yeni bir akımdır. Bu akımın doğmasinda toplumsal yapıya özgü kontrol altına alınamayan değişkenler etkili olmaktadır (Alkibay, 1996, s.416). Bu değişkenlerin en başında teknoloji ile kültürümüze giren özenti temelli moda karmaşasıdır.

Şimdiye kadar doğrudan bir il veya ilçede yer alan iş yeri Adları ile ilgili birçok çalışma yapılmıştır: (Akalın, 2002; Alkibay, 1996; Aksel, 1976; Apak, 2014; Arslan vd., 2018; Arvas, 2011; Boyraz, 2003; Börekçi, 1993; Demircan, 2001; Ertane vd, 2005; Gaddar, 2014; Kandemir, 2014; Karademir, 2004, Kartallığlu, 2001; Kaya, 2008; Küçük, 2007; Küçük vd, 2008; Köktekin vd, 2006; Mert vd., 2014; Mert, 2009; Sancak vd., 2008; Soğanc1, 2000; Şanll, 1999; Üstünova vd., 2010; Üstünova, 1996; Yaman vd., 2016). Bu çalışmaların sonucunda varılan ortak nokta günlük hayatta yabancı sözcüklerin artmasıyla iş yeri adarında yabancı sözcük kullanımında artışın görülmesidir. İşyeri adlarındaki bu yabancılaşma serüveni dilimizdeki kirliliğe örnek olabilecek en önemli alanlardan biridir (Mert ve Türkmen, 2015, s.599). Yabancı unsurların iş yerlerine ad olarak verilmesi, yabancı dillere has sembol veya eklerin iş yeri isimlerinde kullanılması bu olumsuzluğu daha da derinleştirmektedir (Gaddar, 2014, s.321). İş yerlerine isim vermede ticari, sosyal, ailevi, kişisel birçok neden olabilmektedir. Bunların yanında dikkat çekme ve özentinin de iş yeri isimlerinin seçiminde etkili olduğunu söylemek mümkündür (Gaddar, 2014, s.320). İşletme sahipleri, iş yerlerine isim verirken verdikleri ismin dikkat çekici ve akılda kalıcı olmasına dikkat etmektedirler. Hatta yapılan işle ilgili birtakım mesajlar içermesi de önemli bir hususiyet olmaktadır. Bu sebeple daha fazla müşteri çekileceğine inanıldığ 1 için çağrışım gücü yüksek kelimeleri seçmeye özen göstermektedirler (Boyraz, 2003, s.2). Bir iş yerine ne kadar iyi bir isim konulursa, oranın duyulma ihtimalinin ve müşteri kitlesi yoğunluğunun o denli fazla olacağ düşünülmektedir (Arvas, 2011, s.8).

Türkiye genelinde son yıllarda iş yeri adlarının yabancı dillerden alınan sözcüklerden oluşuyor olması ana dilden uzak bir yapılaşmayı gözler önüne sermektedir. Eskiden iş yerlerine daha çok işletme sahibinin adı veya soyadı verilirken artık daha iyi satış yapabilmek ve iş yerlerini ilgi çekici kılmak gibi kaygılardan ötürü soyadları dışında ilginç, kısa, akılda kalabilen isimler tercih edilmektedir. Bir dönem Arapça ve Farsça gramer yapılarının Türkçeye girmesi sorunu günümüzde de İngilizce ile devam ettiği görülmektedir. “Özellikle Osmanlılar zamanında ilmî eserlerin Arapça, edebî ürünlerin de Farsça yazılmasıyla, bu dillerden çok sayıda sözcük ve yapı, Türkçeye girmiş 
ve kirlenme süreci, bir bakıma bu dönemde başlamıştır. 16, 17 ve 18. yüzyıllarda âdeta Arapça ve Farsçanın istilasına uğrayan Türkçeye, Tanzimat'la birlikte batı dillerinden bilhassa Fransızcadan pek çok sözcük girmiştir. O dönemdeki Fransızca temayülü, günümüzde yerini İngilizce özentisine bırakmıştır" (Köktekin ve Kara, 2006, s.506). Türkçenin günümüzde İngilizce ile işgal ediliyor olması, sadece kelime alıntılarından ibaret değildir. (Gülsevin, 2006, s.155-156). İş yeri isimlerindeki anlaşılmaz yabancılaşma o denli yaygın bir hâle gelmiştir ki bu durum sosyolojik ve psikolojik olarak da ele alınmalıdır (Gülsevin, 2006, s.147). Moda karmaşası veya moda takıntısı olarak adlandırabileceğimiz bu durum kültürel yozlaşmayı ve dil kirliliğini beraberinde getirmektedir.

Maddi veya manevi çıkarın dildeki yozlaşmayı ileriye götürmesi sorgulanması ve düzeltilmesi gereken bir alandır. Eğer sorgulanmaz ve düzeltilmezse dilden ve kültürden uzak bir yaşam tarzı kaçınılmaz bir sondur.

\section{Kayseri'ye Bağlı Develi İlçesinin Sosyo - Ekonomik Durumu Hakkında}

İç Anadolu Bölgesinin önemli merkezlerinden biri olan Kayseri'ye bağlı Develi ilçesinin 2016 TÜIK raporlarına göre genel nüfusu 64.422'dir. Esnaf ve Sanatkârlar Odası kayıtlarına göre 1450 kayıtlı esnaf bulunmaktadır. Halkın geçim kaynağı daha çok tarım ve hayvancılık olup sadece Develi Ziraat Odasına kayıtlı olan çiftçi sayısı 10.000'dir. İlçede 400 esnaftan oluşan küçük bir sanayi sitesi bulunmaktadır (Somuncu, 2018: s. 16) ${ }^{1}$. Bu küçük ilçe ekonomik nedenlere bağlı olarak göç vermeye daha meyilli bir yer iken Kayseri Üniversitesi'nin resmî olarak açılması ve ilçede üniversite bünyesinde bazı fakültelerin yer alması, ilçenin son yıllardaki göç verme potansiyelini zayıflatmış, hatta maden ocağının kurulması ile birlikte ilçenin ekonomisinin canlandığı görülmektedir.

\section{Çalışmanın Amacı}

Tüketici ve üretici / satıcı arasında bir çeşit iletişim aracı olan iş yerlerinin isimlerinde son yıllarda görülen yabancı dillerin etkisi sınır tanımaz bir hâl

\footnotetext{
${ }^{1}$ Ahmet Şükrü Somuncu tarafından 2018 yılında yüksek lisans tezi olarak çalışılmış olan Develi illçesi Esnaf Dili adlı tezdeki veriler tamamen esnafların konuştuğu dil ile ilgili olup söz konusu makalede yer alan iş yeri adlarının hiç biri bu tezde yer almamaktadır.
} 
almıştır. Bu çalışmanın amacı, küreselleşmeyle gelen yabanclara ve yabancı dillere özentinin küçük bir ilçe olan Develi'nin iş yeri isimlerinde nasıl bir iz bıraktığının değerlendirilmesidir. Bu değerlendirme ile iş yeri isimlerinin hem dil hem kültür bağlamında analiz edilmesi amaçlanmaktadır.

\section{Bulgular}

\section{Gıda Sektöründeki İş Yeri Adları}

Adana Simit Dünyası (öz. is. + Ar. + Ar.) "İşletme sahibi memleketinin adını iş yerine isim olarak vermiştir."; Ali Baba Çorba Salonu (öz. is. + T. + Far. + Fran.) "İşletme sahibi lakabını iş yerine isim olarak vermiştir."; Anadolu Sofrası (Yun. + Ar.); Ankara Kadayıf Yufka (öz. is. + Ar. + T.) "İşletme sahibi memleketini iş yerine isim olarak vermiştir."; Asmalı Konak Lokantası (T. + T. + İt.); Ataman Esnaf Lokantası (öz. is. + Ar. + İt.) "İşletme sahibi soyadını iş yerine isim olarak vermiştir."; Ayhan Ustanın Yeri (öz. is. + T. + T.) "İşletme sahibi adın iş yerine isim olarak vermiştir."; Bakırdă̆ı Bakkaliyesi (öz. is. + Ar.) "İşletme sahibinin köyünün adını iş yerine isim olarak vermiştir."; Bakırdağı Manavı (öz. is. + Rum.) "İşletme sahibi köyünün adın iş yerine isim olarak vermiştir."; Barış Büfe (T. + Fran.); Başarı Baharat (T. + Ar.); Benian Pastanesi (T. + T. + İt. + Far.) "Türkçe isim koyan işletme sahibi dikkat çekici olmak için beni + an ismini tercih etmiştir." Bozkır Gıda (T. + Ar.); Börekçim (T.); Büyükkılı̧ Kuruyemiş (T. + T.); Cafe Gurme (İng. + Fran.) "İşletme sahibi Türkçe dil kurallarına aykırı olan bu ismi dikkat çekmek ve modaya ayak uydurmak için iş yerine isim olarak vermiştir."; Cafe Miss (İng. + İng.) "İşletme sahibi Türkçe dil kurallarına aykırı olan bu ismi dikkat çekmek ve modaya ayak uydurmak için iş yerine isim olarak vermiştir."; Cevizli Gross (Ar. +T. + İt.) "İşletme sahibi soyadını iş yerine isim olarak vermiş ve büyük bir market olduğunu göstermek için gross ismini kullandığını böylece modaya ayak uyduracağına inanmıştır.", Çarşı Döner (Far. + T.) "İşletme Develi meydanında yer alması sebebiyle bu isim işletme sahibi tarafından iş yerine isim olarak verilmiştir."; Çekemoğlu Market (T. + İng.) "İşletme sahibi soyadını iş yerine isim olarak vermiştir."; Çiftçi Ekmek Fabrikası (T. + T. + İt.) "İşletme sahibi soyadını iş yerine isim olarak vermiştir."; Çizmeli Kasabı (T. + Ar.) "İşletme sahibi soyadını iş yerine isim olarak vermiştir."; Develi Et Dünyası (YA + T. + Ar.) "İşletme sahibi memleketini iş 
yerine isim olarak vermiştir."; Develi Gross (öz. is. +İt.) "İşletme sahibi memleketini iş yerine isim olarak vermiştir."; Durak Etli Pide Salonu (T. + T. + Rum. + Fran.) "İşletme mekân olarak köy otobüsleri durağının yanında olması sebebiyle bu ismi almıştır."; Ege Taş Ekmek Fırını (öz. is. + T. + T. + Rum.) "İşletme sahibi Ege ismi ile dikkat çekmek istemiştir." Ehl-i Keyf Kafe (Ar. + Ar. + İng.) "İşletme sahibi modaya ayak uydurmak amaciyla iş yerine Arapça tamlamadan oluşan bir isim vermiştir."; Ekonomik Manav (Fran. + Rum.); Emmioğlu Develi Cıvıklısı (Ar. + T. + öz. is. + T.) "İşletme sahibi daha çok müşteri çekmek için bu ismi iş yerine vermiştir."; Emmioğlu Kasabı (Ar. + T. + Ar.) "İşletme sahibi daha çok müşteri çekmek için bu adı iş yerine isim olarak vermiştir."; Eseroğlu Kebap Salonu (öz. is. + Ar.) "İşletme sahibi soyadını iş yerine isim olarak vermiştir."; Gözde Lokantası (T. + İt. ) "İşletme sahibi daha çok müşteri çekmek için bu ismi iş yerine vermiştir."; Gözde Yöresel Et ve Süt Ürünleri (T. + T. + T. + Ar. + T. + T.) "İşletme sahibi daha çok müşteri çekmek için bu ismi vermiştir."; Güçlü Gıda Pazarn (T. + Ar. + Far.); Güldesteler Manavı (Öz. is. + Rum. ) "İşletme sahibi, soy adını işletmeye isim olarak vermiştir."; Günebakan Tantuni (T. + ?) "İşletme sahibi bu mekânı önce kahvaltı salonu olarak açmıştır daha sonra kebap salonu olarak kullanmıştır. Günebakan ile kahvaltı arasında bir ilgi kurmuş olması sebebiyle bu ismi iş yerine vermiştir."; Inci Pastanesi (T. + İt. + Far.); Inci Tekel (T. + T.); Kanlı Kasabın Yeri (T. + Ar. + T.) "İşletme sahibinin lakabı olan kanlı kelimesi iş yerine isim olarak verilmiştir."; Karadeniz Ekmek - Unlu Mamülleri (öz. is. + T. + T. + Ar.) "İşletme sahibinin Karadeniz bölgesine özgü ekmek üretiyor ve satıyor olmasından ötürü bu ad iş yerine isim olarak verilmiştir."; Kardeşler Sebze Meyve Halk Pazarı (T. + Far. + Far. + Ar. + Far.) "Üç kardeş tarafından açılan bu işletme ismini kardeş olmaları sebebiyle almıştır."; Kel Bekirin Yeri (öz. is. + T.) "İşletme sahibi lakabını iş yerine isim olarak vermiştir."; Kemeraltı Develi Cıvıklısı (öz. is. +T. + T.) "Tarihî konumu sebebiyle bu isim kullanılmıştır."; Kısmet Çay Evi (Ar. + Çin. + T.); Kısmet Develi Cıvıklısı (Ar. + T. +T.); Kolsuzlar Et Market (T. + T. + İng. ) "İşletme sahibi soyadını iş yerine isim olarak vermiştir."; Köşem Kuruyemiş (Far. + T.) "Mekân olarak Develi meydanının kesiştiği yerde olması sebebiyle bu isim verilmiştir."; Lezzet Develi Cıvıklısı (Ar. + T. + T.) "Müşterinin dikkatini çekmek amacıyla iş yerine bu isim verilmiştir."; Mangalcı Paşa Dayı (Ar. + T. +T.) "İşletme sahibinin lakabının Paşa Dayı olması sebebiyle kebap salonu olan bu mekâna böyle isim verilmiştir."; Meydan Kuruyemiş Şekerleme (Ar. + T. 
+ Far. + T.) "Mekânın bulunduğu yer sebebiyle işletmeye böyle bir isim verilmiştir."; Milano Pastanesi (Öz. is. + İt. +Far.) "Modaya ayak uydurmak amacıyla yabancı bir ülkede yer alan bir şehrin adı işletmenin ismi olmuştur."; Mutlu Ekmek Fabrikası (T. +T. + İt.) "İşletme sahibi soyadını iş yerine isim olarak vermiştir."; Onurlife Dining Holl-Restaurant (Fran. + İng. + İng. + Fran.) "Modaya ayak uydurmak ve dikkat çekici olmak için işletmeye bu isim verilmiştir."; Öz Develi Kadayıf Yufka (T. + T. + Ar. + T.) "İşletme sahibi memleketini iş yerine isim olarak vermiştir."; Öz Develi Kasabı (T. + T. + Ar.) "İşletme sahibi memleketini iş yerine isim olarak vermiştir." ; Palanın Yeri (öz. is. + T.) "İşletme sahibi lakabını iş yerine isim olarak vermiştir."; Palmiye Pastanesi (Fran. +İt. + Far.) "Dikkat çekici olmak için işletmeye bu isim verilmiştir."; Papatya Market (Rum. + İng.); Pınar Et Sitesi (T. + T. + Fran.) "İşletme sahibi çocuğunun adını mekânuna isim olarak vermiştir."; Saray Tatlı (Far. + T.); Seyrani Unlu Mamülleri (Öz. is. + T.+ Ar.) "Mekân sahibi Develili halk âşığının adını mekânına isim olarak vermiştir." ; Seyrani Kıraathanesi (öz. is. + Ar. + Far.) "İşletme sahibi Develili halk âşığının adını iş yerine isim olarak vermiştir." ; Şifa Çorba ve Sulu Yemek (Ar. + Far. + Ar. + T. + T.) "Dikkat çekici olmak için işletmeye bu isim verilmiştir."; Tekir Et Sitesi (öz. is. + T. + Fran.) "Erciyes dağının bulunduğu konuma Tekir denmesinden dolayı iş yerine bu isim verilmiştir."; Titiz Baharat (T. + Ar.) "İşletme sahibinin lakabı iş yerine isim olarak verilmiştir."; Tokluoğlu Kasabı (öz. is. + Ar.) "İşletme sahibi soyadını iş yerine isim olarak vermiştir."; Tuzcu Tuzsuz Hasan (T. + T. + Öz. is.) "İşletme sahibinin lakabı iş yerine isim olarak verilmiştir."; Uzunyayla Kasabı (öz. is. + Ar.) "İşletme sahibi köyünün adını iş yerine isim olarak vermiştir." Ülüler Ekmek Fabrikası (öz. is. + T. + İt.) "İşletme sahibi soyadını iş yerine isim olarak vermiştir."; Yalçınlar Market (öz. is. + İng.) "İşletme sahibi soyadını iş yerine isim olarak vermiştir."; Yeter Gıda (öz. is. + Ar.) "İşletme sahibi soyadını iş yerine isim olarak vermiştir."; Yüzüncü Yıl Kıraathanesi (T. + T. + Ar. + Far.); Zafer Market (öz. is. + İng.) "İşletme sahibi babasının adını iş yerine isim olarak vermiştir."; Zirve Bilardo Salonu (Ar. + İt. + Fran.) "İşletme sahibi dikkat çekmek için bu adı iş yerine isim olarak vermiştir."

\section{Mobilya Sektöründeki İş Yeri Adlarn}

Ürgüplüler Ticaret-Mobilya (öz. is. + Ar.) "İşletme sahibi memleketini iş yerine isim olarak vermiştir."; Çelen Mobilya (öz. is. + İt.) "İşletme sahibi soyadını iş 
yerine isim olarak vermiştir."; Elif Mobilya (öz. is. + İt.) "İşletme sahibi çocuğunun adını iş yerine isim olarak vermiştir."

\section{Sağhk Sektöründeki İş Yeri Adlarn}

Eczane 2000 (Ar. + Far. + s.a.) "İşletme sahibi iş yerini 2000 yılında açması sebebiyle iş yerine bu ismi vermiştir."; Aydm Eczanesi (öz. is. + Ar. + Far.) "İşletme sahibi adını iş yerine isim olarak vermiştir."; Selma Eczanesi (öz. is. + Ar. + Far.) "İşletme sahibi adını iş yerine isim olarak vermiştir."; Erciyes Eczanesi (öz. is. + Ar. + Far.) "İşletme sahibi Erciyes Dağının adını iş yerine isim olarak vermiştir."; Eren Eczanesi (öz. is. + Ar. + Far.) "İşletme sahibi adını iş yerine isim olarak vermiştir."; Okur Eczanesi (öz. is. + Ar. + Far.) "İşletme sahibi soyadını iş yerine isim olarak vermiştir."; Develi Eczanesi (öz. is. + Ar. + Far.) "İşletme sahibi memleketini iş yerine isim olarak vermiştir."; Şifa Eczanesi (Ar. + Ar. + Far.) "İşletme sahibi müşteri ile sağlık sektöründe iyi bir bağ kurmak amacıyla iş yerine bu ismi vermiştir."; Ilhan Eczanesi (öz. is. + Ar. + Far.) "İşletme sahibi soyadını iş yerine isim olarak vermiştir."; Hastaneler Eczanesi (Far. + Ar. + Far. ) "İşletme sahibi mekânının bulunduğu konumdan ötürü bu adı iş yerine isim olarak vermiştir."; Kılıç Eczanesi (öz. is. + Ar. + Far.) "İşletme sahibi soyadını iş yerine isim olarak vermiştir."; Meydan Eczanesi (Ar. + Ar. + Far.) "İşletme sahibi mekânının bulunduğu konumdan ötürü bu adı iş yerine isim olarak vermiştir."

\section{Nalbur-Hırdavat-Yapı Malzemeleri Sektöründeki İş Yeri Adlarn}

Kılıçaslan Elektrik (öz. is. + Fran.) "İşletme sahibi soyadını iş yerine isim olarak vermiştir."; Kardeşler Nalburiye (T. + Ar. + Far.); Dörtler Elektrik (T. + Fran.) "İşletme dört ortak ile açıldığından dolayı iş yerine bu isim verilmiştir."; Maraşhooğlu Hırdavat (öz. is. + Far. + Ar.) "İşletme sahibi soyadını iş yerine isim olarak vermiştir, aynı zamanda işletme sahibi Maraşlıdır."; Kayhan Ticaret (Öz. is. + Ar.) "İşletme sahibi adını iş yerine isim olarak vermiştir"; Cengizhan Ticaret-Nalburiye (Öz. is. + Ar. + Ar. + Far.) "İşletme sahibi soyadını iş yerine isim olarak vermiştir."; Kolay Elektrik (Öz. is. + Fran.) "İşletme sahibi soyadını iş yerine isim olarak vermiştir."; Özdilek Ticaret (Öz. is. + Ar.) "İşletme sahibi soyadını iş yerine isim olarak vermiştir."; Yansın Elektrik (Öz. is. + Fran.) "İşletme sahibi lakabını iş yerine isim olarak vermiştir." 


\section{İnşaat-Emlak Sektöründeki İş Yeri Adlan}

Gürbüz Emlak (öz. is. + Ar.) "İşletme sahibi soyadını iş yerine isim olarak vermiştir."; Ertaş İnşaat (öz. is. + Ar.) "İşletme sahibi ad ve soyadlarının ilk hecelerini iş yerine isim olarak vermiştir.”; Demircioğlu İnşaat (öz. is. + Ar.) “İşletme sahibi soyadını iş yerine isim olarak vermiştir."; Mangal Group İnşaat (Ar. + Fran. + Ar.) "İşletme sahibi soyadını ve dikkat çekmek için de group kelimesini iş yerine isim olarak vermiştir."; Süsler Pen (T. + Far.) "İşletme sahibi ilgi çekici olması için pencere kelimesinin sadece ilk hecesini kullanarak iş yerine isim vermiştir."; Fatih Emlak (öz. is. + Ar.) "İşletme sahibi adını iş yerine isim olarak vermiştir."; MGM Kardeşler İnşaat (öz. is. + T. + Ar.) "İşletme sahibi olan üç kardeş isimlerinin baş harflerini iş yerlerine isim olarak vermişlerdir."

\section{Giyim-Ayakkabı ve Tekstil Sektöründeki İş Yeri Adlan}

Elif Çocuk Giyim (öz. is. + T. + T.) "İşletme sahibi çocuğunun adını iş yerine isim olarak vermiştir."; Kartın Ticaret (öz. is. + Ar.) "İşletme sahibi soyadını iş yerine isim olarak vermiştir."; Mesut Giyim (öz. is. + T.) "İşletme sahibi adını iş yerine isim olarak vermiştir."; Nuray Giyim (öz. is. + T.) "İşletme sahibi eşinin adını iş yerine isim olarak vermiştir."; Hisar Giyim (öz. is. + T.) "İşletme sahibi yer adını iş yerine isim olarak vermiştir."; Gözde Kundura (T. + İt.) "İşletme sahibi dikkat çekici olmak için bu adı iş yerine isim olarak vermiştir."; İslamoğlu Tekstil (öz. is. + Fran.) "İşletme sahibi soyadını iş yerine isim olarak vermiştir."; Butik Melike (Fran. + öz. is.) "İşletme sahibi çocuğunun adını iş yerine isim olarak vermiştir."; Aygim Ayakkabıcılık (öz. is. + T.) "İşletme sahibi ayakkabı ve giyim kelimeleri kısaltarak iş yerine isim olarak vermiştir."; Saray Perde (Far. + Far.) "İşletme sahibi dikkat çekmek için bu adı iş yerine isim olarak vermiştir." Elit Perde (Fran. + Far.) "İşletme sahibi dikkat çekmek için bu adı iş yerine isim olarak vermiştir."; Damla Perde (öz. is. + Far.) "İşletme sahibi çocuğunun adını iş yerine isim olarak vermiştir."; Yaşar Tekstil (öz. is. + Fran.) "İşletme sahibi adını iş yerine isim olarak vermiştir."; A $\breve{g} c a$ Iç̧ Giyim (öz. is. + T. + T.) "İşletme sahibi soyadını iş yerine isim olarak vermiştir."; Rengarenk $\dot{I}_{c ̧}$ Giyim (Far. + T. + T.) "İşletme sahibi dikkat çekici olmak için bu adı iş yerine isim olarak vermiştir."; Bazaar Giyim (Far. + T.) "İşletme sahibi dikkat çekici olmak için bu adı iş yerine isim olarak vermiştir."; Ça Ş̧̧ $_{\text {Giyim }}$ (Far. + T.) "İşletme sahibi tutmuş olduğu futbol takımına özenerek bu adı iş yerine isim olarak vermiştir.”; Yiğit Giyim (öz. is. + T.) "İşletme sahibi soyadını iş yerine 
isim olarak vermiştir."; Küçükoğlu Ayakkabı (öz. is. + T.) "İşletme sahibi soyadını iş yerine isim olarak vermiştir."; Ah-sen Kundura (T. + İt.) "İşletme sahibi dikkat çekici olmak için bu adı iş yerine isim olarak vermiştir."; NT Spor (öz. is. + Fran.) "İşletme sahibinin adı ve soyadının baş harflerini iş yerine isim olarak verilmiştir."; Masmas Kundura Giyim (öz. is. + T.) "İşletme sahibi soyadını iş yerine isim olarak vermiştir."; Eva Butik (Ar. + Fran.) "Işsletme sahibi eva isminin anlamından yola çıkarak bu adı iş yerine isim olarak vermiştir."; Zeki Kundura (öz. is. + İt.) "İşletme sahibi soyadını iş yerine isim olarak vermiştir."

\section{Kuaför-Berber Sektöründeki İş Yeri Adlarn}

İstanbullu Erkek Kuaförü (öz. is. + T. + Fran.) "İşletme sahibi lakabını iş yerine isim olarak vermiştir."; Şanel Bayan Kuaförü (Öz. is. + T. + Fran.) "İşletme sahibi adını iş yerine isim olarak vermiştir."; Reform Bayan Kuaförü (Fran. + T. + Fran.) "İşletme sahibi dikkat çekmek amaciyla iş yerine bu ismi vermiştir."; Zeynep Bayan Kuaförü (öz. is. + T. + Fran.) "İşletme sahibi adını iş yerine isim olarak vermiştir."; Cafune Bayan Kuaförü (Por. + T. + Fran.) "İşletme sahibi Cafune adını bilinçli olarak koymuştur. Cafune sevgilinin saçlarında şefkatle parmakların gezdirmek anlamındadır (Erişim Adresi ve tarihi: https://portekizce-turkce.cevirsozluk.com/ceviri2/35431285-cafune, 21.05.2020)."; İsa Erkek Kuaförü (öz. is. + T. + Fran.) "İşletme sahibi adını iş yerine isim olarak vermiştir."; Fatih Erkek Kuaförü (öz. is. + T. + Fran.) "İşletme sahibi adını iş yerine isim olarak vermiştir."; Mavi Boncuk Erkek Kuaförü (Ar. + T. + T. + Fran.) "İşletme sahibi dikkat çekmek amaciyla iş yerine bu ismi vermiştir." ; Arkadaş Erkek Kuaförü (T. + T. + Fran.) "İşletme sahibi müşteri ile yakınlık kurmak amacıyla bu adı iş yerine isim olarak vermiştir."; Ŭğur Erkek Kuaförü (öz. is. + T. + Fran.) "İşletme sahibi adını iş yerine isim olarak vermiştir."; Yaşar Erkek Kuaförü (öz. is. + T. + Fran.) "İşletme sahibi soyadını iş yerine isim olarak vermiştir."; Makkas Kuaför Salonu (Ar. + Fran. + Fran.) "İşletme sahibi dikkat çekmek amacıyla iş yerine bu ismi vermiştir.”; Tarzım Erkek Kuaförü (Ar. + T. + Fran.) "İşletme sahibi dikkat çekmek amaciyla iş yerine bu ismi vermiştir."; Salon İstanbul (Fran. + öz. is.) "İşletme sahibi dikkat çekmek amacıyla iş yerine bu ismi vermiştir.”; Yeşil Everek Erkek Kuaförü (öz. is. + T. + Fran.) “Develinin eski adı olan 
Yeşil Everek işletme sahibinin memleketi olup, işletme sahibi bu adı memleketi olması sebebiyle iş yerine isim olarak vermiştir." Firat Erkek Kuaförü (öz. is. + T. + Fran.) "İşletme sahibi soyadını iş yerine isim olarak vermiştir."

\section{Ĕ̆lence-Oyun ve İnternet Salonlarn ile Teknolojik Mağaza Sektöründeki İş Yeri Adlarn}

Gazioğlu Bilişim (öz. is. + T.) "İşletme sahibi dedesinin adını iş yerine isim olarak vermiştir."; Alp Dijital Reklam (öz. is. + Fran. + Fran.) "İşletme sahibi çocuğunun adını iş yerine isim olarak vermiştir."; Süper Reklam (Fran. + Fran.) "İşletme sahibi dikkat çekmek için bu adı iş yerine isim olarak vermiştir."; Export Bilgisayar (İng. + T.) "İşletme sahibi dikkat çekmek için bu adı iş yerine isim olarak vermiştir."; Statik İnternet Cafe (Fran. + İng. + İng.) "İşletme sahibi dikkat çekmek için bu adı iş yerine isim olarak vermiştir."; Atom Karınca Playstation (öz. is. + İng.) "İşletme sahibi internette oynanan bir oyun adını iş yerine isim olarak vermiştir."; Flash Elektronik (İng. + Fran.) "İşletme sahibi dikkat çekmek için bu adı iş yerine isim olarak vermiştir."; Öztürk Elektronik (öz. is. + Fran.) "İşletme sahibi soyadını iş yerine isim olarak vermiştir."; Ufuk GSM (öz. is. + İng.) "İşletme sahibi adını iş yerine isim olarak vermiştir."; Efe İletişim (öz. is. + T.) "İşletme sahibi çocuğunun adını iş yerine isim olarak vermiştir."; Musti İletişim (öz. is. + T.) "İşletme sahibi lakabını iş yerine isim olarak vermiştir."; Barış Tekno İletişim (öz. is. + Fran. + T.) "İşletme sahibi çocuğunun adını iş yerine isim olarak vermiştir."; Kılınç Telefon Aksesuar (öz. is. + Fran. + Fran.) "İşletme sahibi soyadını iş yerine isim olarak vermiştir.";

\section{Otomotiv-Oto Malzemeleri ve Oto Tamir Sektöründeki İş Yeri Adlan}

Kayseri Otomotiv (öz. is. + İng.) "İşletme sahibi memleketini iş yerine isim olarak vermiştir."; Zirve Oto Yikama (Ar. + İng. + T.) "İşletme sahibi dikkat çekmek için bu adı iş yerine isim olarak vermiştir."; Vefa Group Otomotiv (Ar. + İng. + İng.); Tokerler Oto Galeri (öz. is. + İng. + Fran.) "İşletme sahibi soyadını iş yerine isim olarak vermiştir."; Karadöl Oto Lastik (öz. is. + İng. + Fran.) "İşletme sahibi soyadın iş yerine isim olarak vermiştir."; Taş Oto Ylkama (öz. is. + İng. + T.) "İşletme sahibi soyadını iş yerine isim olarak vermiştir."; Müderrisoğlu Oto Galeri (öz. is. + İng. +Fran.) "İşletme sahibi soyadın iş yerine isim olarak vermiş̧tir." 


\section{Isınma-Soğutma-Su Tesisatçılı̆̆ı Sektöründeki İş Yeri Adlan}

Samgan Sobacısı (öz. is. + Mac. +T.) "İşletme sahibi soyadını iş yerine isim olarak vermiştir."; Köseoğlu Soğutma (öz. is. + T.) "İşletme sahibi soyadını iş yerine isim olarak vermiştir."; Erdem Sihhi Tesisat (öz. is. + Ar. + Ar.) "İşletme sahibi soyadını iş yerine isim olarak vermiştir."; Kaliberler Odun Kömür (öz. is. + T. + T.) "İşletme sahibi soyadını iş yerine isim olarak vermiştir."

\section{Turizm-Otelcilik Sektöründeki İş Yeri Adlarn}

Otel Kattaş (Fran. + öz. is.) "İşletme sahibi soyadını iş yerine isim olarak vermiştir."; Erciyes Hotel (öz. is. + Fran.) "İşletme sahibi Erciyes Dağının adını iş yerine isim olarak vermiştir."; Başaran Otel (öz. is. + Fran.) "İşletme sahibi soyadın iş yerine isim olarak vermiştir."; Çağrı Otel (öz. is. + Fran.); Efe Tur (T. + Fran.); Öz Develi Tur (T. + öz. is. + Fran.) "İşletme sahibi memleketinin adını iş yerine isim olarak vermiştir."

\section{Fotoğrafçılık Sektöründeki İş Yeri Adlarn}

Foto Yılmaz (Fran. + öz. is.); Foto Yiğit (Fran. + Öz. is.) "İşletme sahibi soyadını iş yerine isim olarak vermiştir."; Foto Selami (Fran. + Öz. is.) "İşletme sahibi adını iş yerine isim olarak vermiştir."; Foto Yıldırım (Fran. + Öz. is.) "İşletme sahibi adını iş yerine isim olarak vermiştir."

\section{Mutfak Eşyalarn ve Züccaciye Sektöründeki İş Yeri Adları}

Birsen Züccaciye (öz. is. + Ar.); Salı Pazarı Avm (T. + Far. + T.) “İşletme sahibi halk pazarının Salı günü olması ve bu pazarda her şeyin ucuz ve oldukça çeşitli olması sebebiyle bu adı iş yerine isim olarak vermiştir."; Akkuş Züccaciye (öz. is. + Ar.) "İşletme sahibi soyadını iş yerine isim olarak vermiştir."; Gönen Züccaciye Avm (öz. is. + Ar. + T.) "İşletme sahibi soyadını iş yerine isim olarak vermiştir." 
Tablo 1. Sektörlere Göre İş Yeri Adlarının Analizi

\begin{tabular}{|c|c|c|c|c|c|c|c|c|c|c|c|}
\hline $\begin{array}{l}\text { Sektörlere Göre İş } \\
\text { Yeri Adları }\end{array}$ & A & $S$ & $\mathbf{L}$ & AA. & MA & KA & DÇ & MAU & S TKA & KY & Yİ \\
\hline \multicolumn{12}{|l|}{ Adana Simit Dünyası } \\
\hline $\begin{array}{l}\text { Ali Baba Çorba } \\
\text { Salonu }\end{array}$ & & & $x$ & & & & & & & & \\
\hline Anadolu Sofrası & & & & & & & & & $x$ & & \\
\hline $\begin{array}{l}\text { Ankara } \\
\text { Kadayıf Yufka }\end{array}$ & & & & & $x$ & & & & & & \\
\hline $\begin{array}{l}\text { Asmalı Konak } \\
\text { Lokantası }\end{array}$ & & & & & & & & & $x$ & & \\
\hline $\begin{array}{l}\text { Ataman Esnaf } \\
\text { Lokantasi }\end{array}$ & & $x$ & & & & & & & & & \\
\hline Ayhan Ustanın Yeri & $x$ & & & & & & & & & & \\
\hline Bakırdağı Bakkaliyesi & & & & & $x$ & & & & & & \\
\hline Bakırdağı Manavı & & & & & $x$ & & & & & & \\
\hline Barış Büfe & & & & & & & & & $x$ & & \\
\hline Başarı Baharat & & & & & & & & & $x$ & & \\
\hline Benian Pastanesi & & & & & & & $x$ & & & & \\
\hline Bozkır Gıda & & & & & & & & & $x$ & & \\
\hline Börekçim & & & & & & & & & $x$ & & \\
\hline $\begin{array}{l}\text { Büyükkılıç } \\
\text { Kuruyemiş }\end{array}$ & & & & & & & & & $x$ & & \\
\hline Cafe Gurme & & & & & & & & $x$ & & & \\
\hline Cafe Miss & & & & & & & & $x$ & & & \\
\hline Cevizli Gross & & $x$ & & & & & & & & & \\
\hline Çarşı Döner & & & & & & $x$ & & & & & \\
\hline Çekemoğlu Market & & $x$ & & & & & & & & & \\
\hline $\begin{array}{l}\text { Çiftçi Ekmek } \\
\text { Fabrikası }\end{array}$ & & $x$ & & & & & & & & & \\
\hline Çizmeli Kasabı & & $x$ & & & & & & & & & \\
\hline Develi Et Dünyası & & & & & $x$ & & & & & & \\
\hline Develi Gross & & & & & & & & $x$ & & & \\
\hline $\begin{array}{l}\text { Durak Etli Pide } \\
\text { Salonu }\end{array}$ & & & & & & $x$ & & & & & \\
\hline Ege Taş Ekmek Furını & & & & & & & $x$ & & & & \\
\hline Ehl-i Keyf Kafe & & & & & & & & $x$ & & & \\
\hline Ekonomik Manav & & & & & & & & & $x$ & & \\
\hline $\begin{array}{l}\text { Emmioğlu Develi } \\
\text { Cıvıklısı }\end{array}$ & & & & & & & $x$ & & & & \\
\hline Emmioğlu Kasabı & & & & & & & $x$ & & & & \\
\hline $\begin{array}{l}\text { Eseroğlu Kebap } \\
\text { Salonu }\end{array}$ & & $x$ & & & & & & & & & \\
\hline Gözde Lokantası & & & & & & & $x$ & & & & \\
\hline $\begin{array}{l}\text { Gözde Yöresel Et } \\
\text { ve Süt Ürünleri }\end{array}$ & & & & & & & $x$ & & & & \\
\hline Güçlü Gıda Pazarı & & & & & & & & & $x$ & & \\
\hline Güldesteler Manavı & & $x$ & & & & & & & & & \\
\hline
\end{tabular}




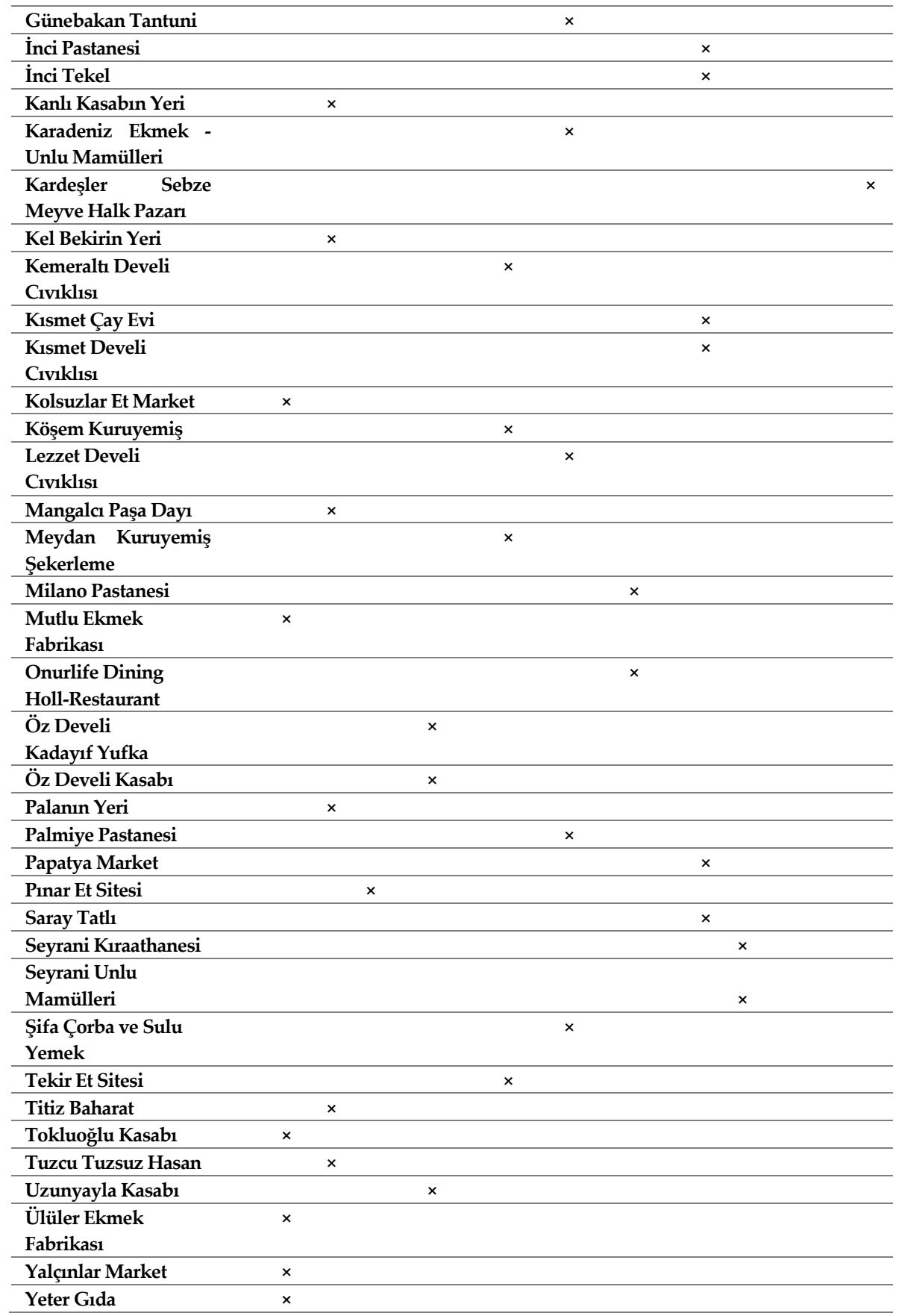




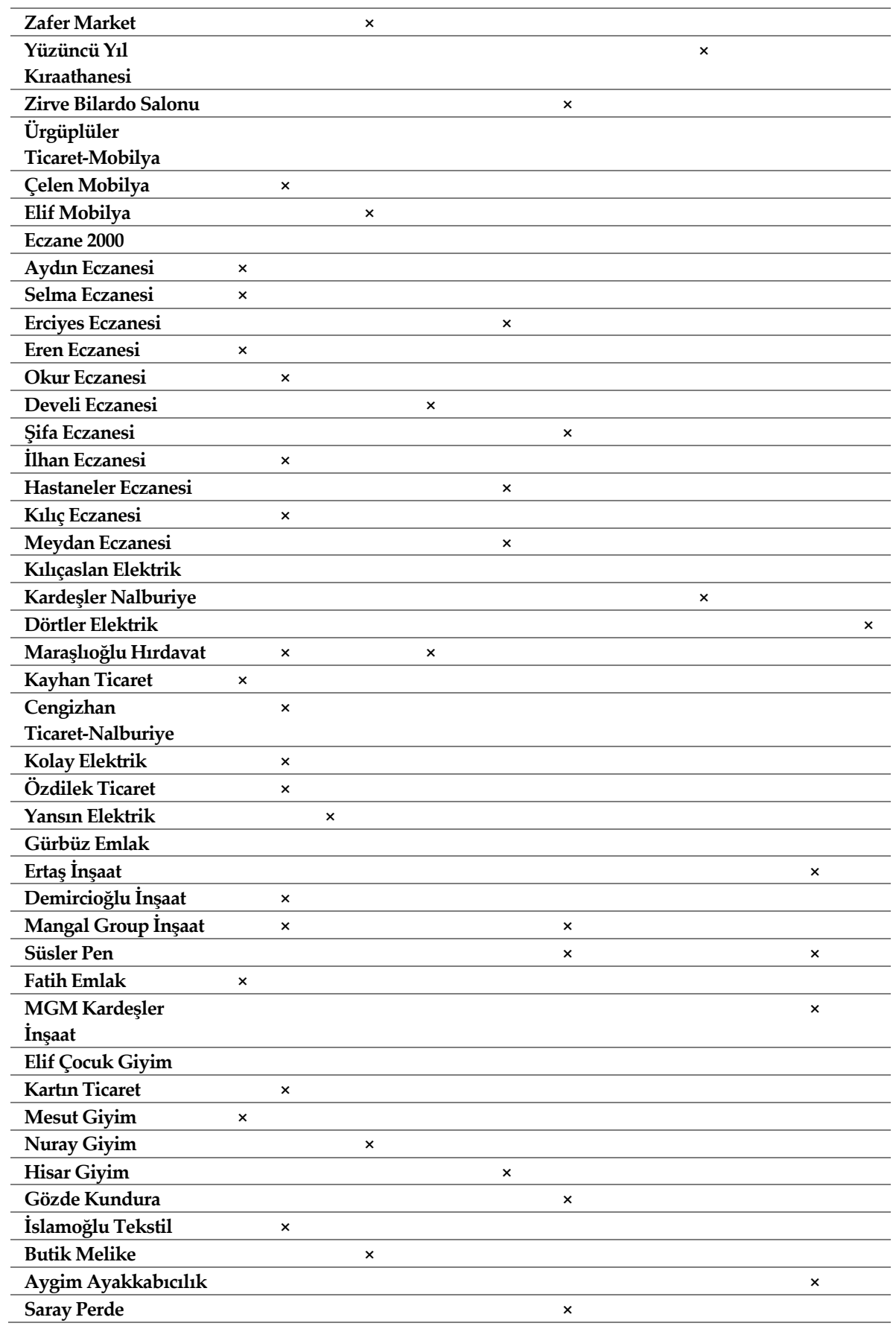




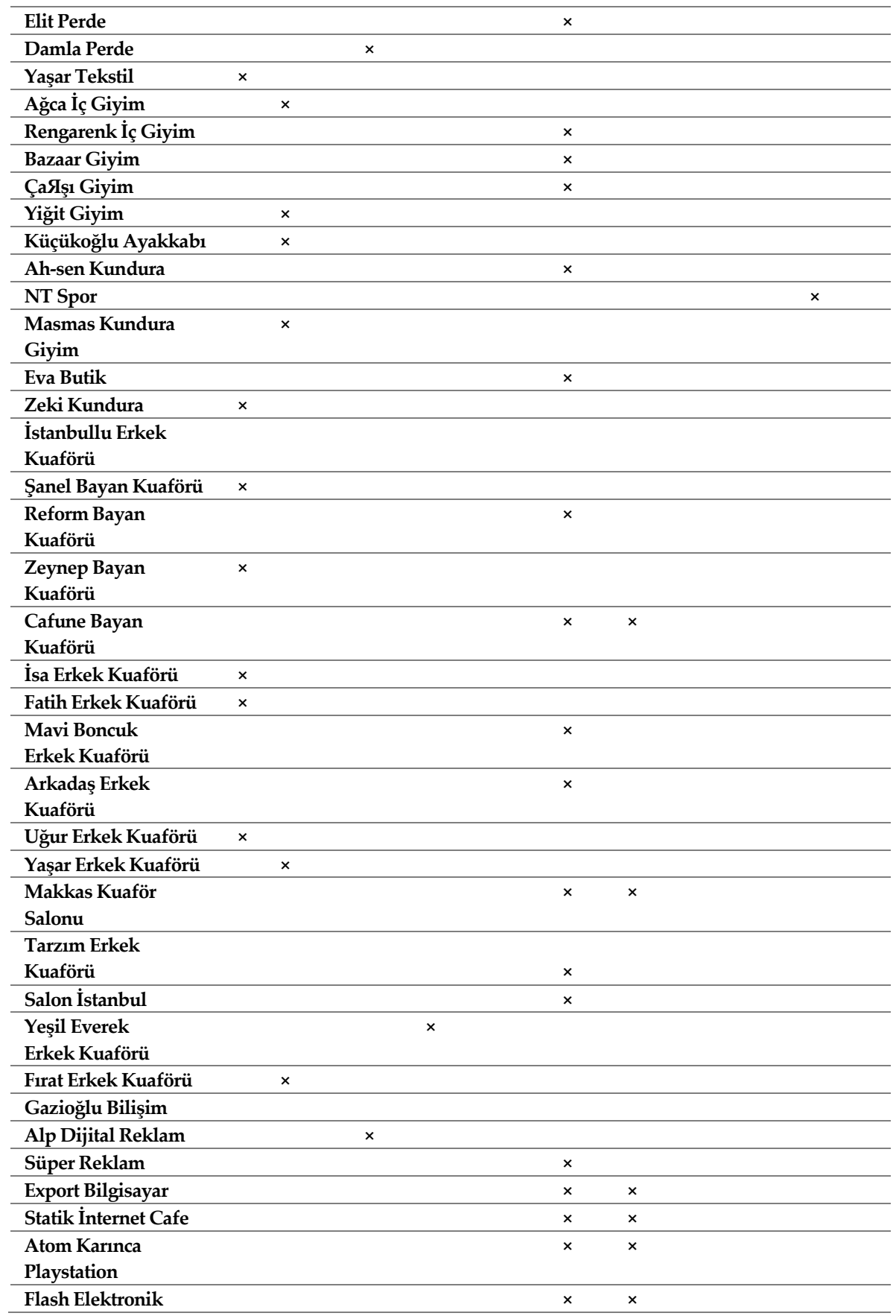




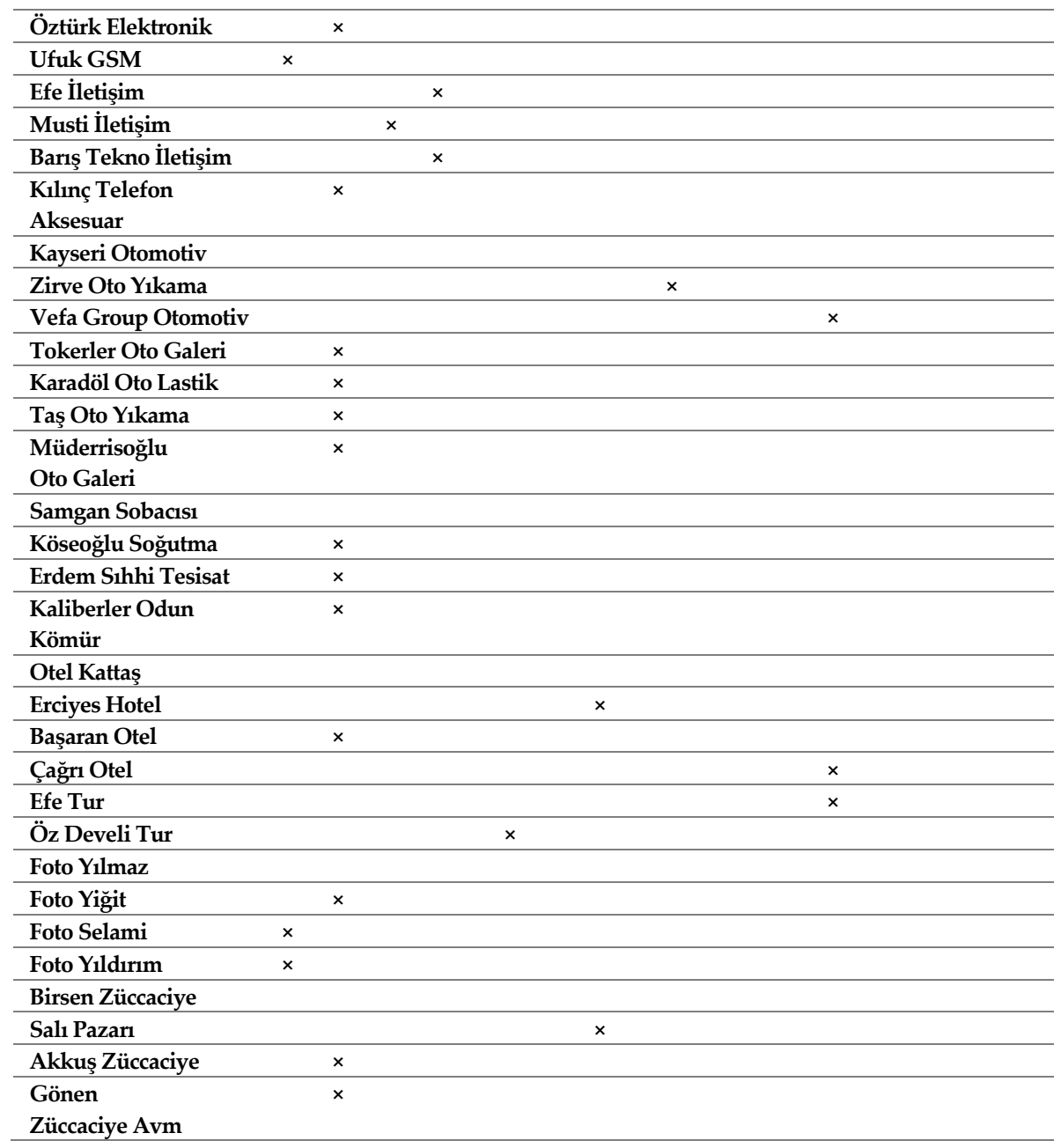

A: Ad yoluyla oluşanlar, S: Soyad yoluyla oluşanlar, L: Lakap yoluyla oluşanlar,

AA: Akraba Adları yoluyla oluşanlar, MA: Memleket Adı yoluyla oluşanlar, KA: Konum Adı yoluyla oluşanlar, DÇ: Dikkat Çekmek amacıyla oluşanlar, MAU: Modaya Ayak Uydurmak amacıyla oluşanlar, S: Sebebi olmaksızın oluşanlar, TKA: Tanınan Kişi Adı yoluyla oluşanlar, KY: Kısaltma Yoluyla oluşanlar, Yİ: Yakın İlişki sebebiyle oluşanlar

\section{Tablo 1'den elde edilen sayısal veriler}

- 17 adet iş yerine işletme sahibinin adı verilmiştir.

- 48 adet iş yerine işletme sahibinin soy adı verilmiştir. 
- 11 adet iş yerine işletme sahibinin akrabalarının adı verilmiştir.

- 14 adet iş yerine işletme sahibinin memleketinin adı verilmiştir.

- 12 adet iş yerine işletmenin bulunduğu konum dolayısıyla isim verilmiştir.

- 37 adet iş yerine işletmenin dikkat çekici olması isteği dolayısıyla isim verilmiştir.

- 10 adet iş yerine işletme sahibinin modaya ayak uydurma isteği dolaylsyyla isim verilmiştir.

- 21 adet iş yerine işletme sahibi tarafından sebebi olmaksızın isim verilmiştir.

- 2 adet iş yerine işletme sahibi tarafından tanınmış kişiler dolayısıyla isim verilmiştir.

- 5 adet iş yerine işletme sahibi tarafından uydurularak, kısaltma yöntemi ile isim verilmiştir.

- 2 adet iş yerine işletme sahibinin yakın ilişki kurduğu kişiler dolayısıyla isim verilmiştir.

\section{Verilerin Analizi}

Ad, soyad, lakap, akraba adı, memleket adı, işletmenin konumu dolayısıyla iş yerlerine verilen isimler çalışmamızın dil bağlamı dışında yer almaktadır. $\mathrm{Bu}$ isimler daha çok işletme sahiplerinin gelenek ve göreneğine bağlı kalarak iş yerlerine verdikleri isimler olduğu için küçük ve kapalı bir toplumu barındıran Develi ilçesi için bu gayet doğal bir durumdur. Bu durum ayrıca geleneğine bağlı bir toplumu göstermekte ve teknoloji, kitle iletişim araçları, yabancllara ve yabanc kültürüne / diline olan özenti gibi dilde yozlaşmaya neden olan sebeplerden etkilenilmemiş olması sevindirici bir durumdur. Türkçe kelimelerin de çoklukla yer aldığı bu ilçenin iş yeri adlarında dikkat çekmek, modaya ayak uydurmak veya nedensiz kısaltmalar da yer almaktadır: Benian Pastanesi: Türkçe iki sözcükten oluşan bu iş yeri adı dil kurallarına uyulmadan birleşik yazılmış ve iş yerinin ismi sanki yeni bir terimin adıymış gibi görünmesine sebep olmuştur. Ege Taş Ekmek Fırını: İşletme sahibinin Ege bölgesine atıf yaparak İç Anadolu bölgesinde bulunan bir ilçede dikkat çekmeyi hedeflemiştir. Emmioğlu Develi Cıvıklısı; Emmioğlu Kasabı: İş yeri Adları işletme sahiplerinin halkla samimi bir diyalog kurma çabasının bir yansımasıdır. Çünkü Anadolu ağızlarında çokça kullanılan emmi sözcüğü yakınlığı 
ve samimiyeti yansıtır. Dolayısıyla işletme sahibi bu yolla dikkat çekip müşteri kazanmayı hedeflemektedir. Gözde Lokantasl; Gözde Yöresel Et ve Süt Ürünleri; Gözde Kundura: İşletme sahipleri Türkçe bir kelime olan Gözde'yi kullanarak bulunduğu ilçede, beğenilen, üstün tutulan bir mekân olmayı hedeflemiştir. Günebakan Tantuni: Türkçe bir isim koyan işletme sahibi mekânını güne başlangıç mekânı olarak düşünüp bu şekilde dikkat çekmeyi hedeflemiştir. Karadeniz Ekmek-Unlu Mamülleri: İşletme sahibinin Karadeniz bölgesine atıf yaparak iç Anadolu bölgesinde bulunan bir ilçede dikkat çekmeyi hedeflemiştir. Lezzet Develi Cıvıklısı: İşletme sahibi mekânındaki yiyeceklerin lezzetli olduğunu göstermek amaciyla bu ismi koymuştur. Palmiye Pastanesi: İşletme sahibi ilçede bulunmayan ve yetişmeyen palmiye ağacının adını iş yerine vererek dikkat çekmeyi amaçlamıştır. Şifa Çorba ve Sulu Yemek: İşletme sahibi iş yerindeki yiyeceklerin şifa kaynağı olduğunu düşünerek ve bu yolla müşteri çekeceğini amaçlayarak bu ismi iş yerine vermiştir. Zirve Bilardo: İşletme sahibi iş yerinin kalite anlamında en yüksekte, zirve noktada olduğunu bildirmek amaciyla bu ismi iş yerine vermiştir. Eczane 2000: İşletme sahibi 2000 yılında bu iş yerini kurmuştur. Dikkat çekmek amacıyla bu isim iş yerine verilse de iş yerinde adı Türkçenin dil kurallarına uymamaktadır. İş yeri adı 2000 Eczanesi şeklinde olmalıdır. Şifa Eczanesi: Tıpkı Şifa Çorba ve Sulu Yemek işletmesindeki gibi müşterilerin şifa bulacağı anlayışı sonucunda verilen bir isimdir. Mangal Group İnşaat: Bu iş yeri isminde yer alan Mangal kelimesi iş yeri sahibinin soyadıdır. Group kelimesi ise tamamıla dikkat çekmeyi amaçlayan ve Türkçe dil mantığına uymayan bir kelimedir. Vefa Group Otomotiv: Burada iş yerinin adı Arapça Vefa ve Fransızca grup, İngilizce otomotiv adından oluştuğu görülmektedir. Vefa ve otomotiv kelimeleri artık dilimize yerleşen ve Türkçeleşmiş kelimelerdendir. Fakat burada group kelimesinin Türkçeleşmiş hali olan grup biçimi kullanılmayarak bir dil hatası yapılmıştır. En azından bu kelime grup şeklinde düzeltilebilir. Süsler Pen: Bu işletme adında en dikkat çekici kısım pencere kelimesinin işletme sahibi tarafından dil kuralı dışında kısaltılarak verilmiş olmasıdır. Elit Perde ve Saray Perde: İşletme sahipleri işletmelerinde üretilen perdenin üst düzey bir kesime hitap ettiğini göstermek ve müşterinin kendi özel hissettirmesini sağlamak amaciyla verilen isimlerdir. Rengarenk Iç Giyim: Isşletme sahibinin iş yerinde her çeşit ve her renkten ürünün bulunduğunu göstermek amaciyla verdiği bir isimdir. Bazaar Giyim: İşletme sahibi Farsça bâzâr kelimesinden esinlenerek ve bu kelimeyi kendine göre değiştirerek iş yerine isim olarak vermiştir. 
Burada, hem kelimenin orijinaline sadık kalınmamış hem de Türkçeleştirilmiş hâli olan pazar kelimesi kullanılmamıştır ve böylece tam bir dil hatası

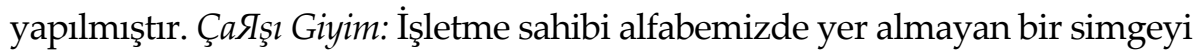
iş yeri adında kullanarak dikkat çekmeyi amaçlamıştır. Çarşı kelimesinde yer alan /r/ ünsüzünü ters kullanarak Türkçe dil kuralına bir aykırılık oluşturulmuştur. Ah-Sen Kundura: Burada Türkçe iki kelimeyi kullanan işletme sahibi Ah ünlemi ile sen zamirini birleştirmiş, iki kelime arasına koyduğu çizgi işareti de dikkat çekiciliği sağlayan bir unsur olmuştur. Eva Butik: Türkçe bir kelime kullanmayan iş yeri sahibi, işletme adıyla anlamı arasında bir bağlantı kurmuştur. Reform Bayan Kuaförü; Cafune Bayan Kuaförü: Her iki işletme ismi de Türkçe olmayıp hem dikkat çekmek hem de modaya ayak uydurmak amaciyla verilmiştir. Makkas Kuaför Salonu: Arapça mikass kelimesinden gelen makas kelimesi işletme sahibi tarafından müdahaleye uğrayarak çift k'li kullanılmış ve dil kuralına aykırılığa neden olmuştur. Salon İstanbul: İşletme sahibi Türkiye'nin en popüler ili olan İstanbul'u iş yerine isim olarak vermiştir fakat burada dikkat çekiciliği ön plana alsa da Türkçe dil kuralına aykırı bir durum söz konusudur. İşletmenin adı İstanbul Salonu şeklinde olmalıdır. Süper Reklam; Export Bilgisayar; Statik Internet Café; Atom Karnca Playstation; Flash Elektronik: $\mathrm{Bu}$ iş yeri adlarının yabancı kökenli olup hem dikkat çekmek hem de modaya ayak uydurmak amaciyla işletme sahipleri tarafından verilmiştir. Cafe Gurme; Cafe Miss: Bu işletme Adları hem Türkçe değildir hem de Türkçe dil kurallarına aykırıdır. Modaya ayak uydurmak amacıyla bu isimler kullanılmıştır. Türkçeleştirilmiş hali olan kafe kelimesi c'li kullanılmış coffee kelimesinden esinlenilmiştir. Türkçe dil yapısına aykırı bir kullanım söz konusudur. Develi Gross: Büyük market anlamına gelen Gross kelimesi işletme sahibi tarafından modaya ayak uydurmak amacıyla kullanılmıştır. Kısaltmalarla kurulan iş yeri adlarından Ertaş İnşaat; Mgm Kardeşler; Aygim Ayakkabıctlık; Nt Spor herhangi bir Türkçe dil kuralına uymaksızın bu isimler iş yerlerine isim olarak verilmiştir.

\section{Sonuç ve Öneriler}

Teknolojinin günlük hayatta baş konuk olarak yer almasıyla beraber Türkçe kelimelerle karşılanıp ifade alanı bulabilecek kelimelerin yabancı dillerdeki karşılığı veya tam versiyonu tercih edilmeye başlanmıştır. Bu durum her alanda yansımasını bulurken iş yeri isimlerinde daha da üst düzeye geçtiği 
tespit edilmektedir. Develi ilçesinde yer alan iş yeri isimlerinin incelendiği bu çalışmada dikkat çeken dil hususiyetlerini, yapılan dil hatalarını ve bazı önerileri sunmak mümkündür:

\section{Doğrudan Türkçe karşıllı̆̆ı verilebilecek iş yeri adları}

İslamoğlu Tekstil ve Yaşar Tekstil, ad ve soy adın verildiği bu iş yeri isimlerinde kültür bağlamında geleneğine bağlı bir toplumun göstergesi ile karşılansa da tekstil kelimesinin Türkçe karşlığı olan dokuma kelimesinin kullanılması daha uygundur.

\section{Geçmişte kullanılan ama şu an yerini başka isimlere bırakan iş yeri adları}

Ülkemizde lokanta veya market kelimeleri daha çok kullanılırken bu kelimelerin yerini Restaurant ve Gross almıştır. Lokanta kelimesi İtalyanca Locanda kelimesinden gelse de kelime Türkçeleştirilmiş ve dilimize uydurulmuştur. Fakat restaurant kelimesi Türkçeleştirilmiş hâli restoran olsa da Fransızcadaki karşılığı ile kullanılmaktadır. Develi iş yeri adları içerisinde restaurant kelimesini sadece Onurlife Dining Holl-Restaurant iş yeri isminde görsek de bu durum ilçenin son ylllarda yeni açlan işletmelere bu tarz isimler verilmesine özendirdiği ve özendireceğini göstermektedir. Diğer işletme isimlerinde lokanta olması bu iş yerlerinin 2000 yılından önce açılması ile ilgilidir. Son yıllarda her yerde olduğu gibi küçük bir ilçe olan Develi'de de market yerine gross kelimesi kullanılmaya başlandığı görülmektedir. Market eskiden bakkal olan iş yerlerinin büyügü olarak nitelendirilirken şimdilerde ise gross marketin büyüğü ve daha ucuz olanı olarak nitelendirilmektedir. Ama incelenen gross ismini taşıyan işletmelerde bu ismin veriliş amacıyla bir ilgisinin bulunmadığını tamamıyla daha dikkat çekmek amacıyla konduğunu göstermektedir. Bunun yerine Büyük Market denilmesi en azında dilimize çok daha yabancı ve uzak olan kelimeden daha uygun bir söz öbeği olabilir, kanaatindeyiz. Eskiden berber olarak kullanılan işletme isimlerine bakıldığında artık berber kelimesinin hiç kullanılmadığını bunun yerine Fransızca kuaför kelimesinin kullanıldığı görülmektedir. Berber kelimesi de Farsça olmasına rağmen geçmişte dilimize uyarlanmış ve yıllarca kullanılmıştır. Fakat şuan 
ticari kaygilar, modaya ayak uydurma gibi nedenler eski, dilimize adapte olmuş kelimeler yerine teknolojiyle dilimize girip yerleşen kelimeleri tercih etme yolundadir.

\section{Kısaltmalarla kurulan iş yeri adlan}

GSM açılımı "Global System for Mobile Communications" olan Türkçesi, "mobil iletişim için küresel sistem" anlamina gelen cep telefonu iletişim protokolü, AVM açılımı ise "Alış Veriş Merkezi"dir. Bu tarz kısaltmalar da Develi ilçesinde yaygın hâle gelmeye başlamıştır. Kısaltarak kullanma yabancı sözcük veya marka havası kattığı için insanlar tarafından daha talep edilmesini arttırmaktadır. GSM kısaltması tam bir alıntı söz öbeğidir. Bu kısaltmadaki esas sıkıntı telaffuzla ilgilidir. Zaten içeriği yabancı kelimelerle oluşmuş bir söz öbeğini İngilizcenin alfabesinin telaffuzuna göre ele almanın dile de zararı oldukça büyüktür. En azından telaffuz şekli Türkçe olması gerekir. Bu tarz kısaltmaların dikkat çekici olması nedeniyle işletme sahibinin adı ve soyadından oluşan ve günümüzde aslında bir marka ismi olan NT Spor da buna bir örnektir. Hem kuruluşu yanlış hem telaffuzu dil kurallarına aykırı bir iş yeri ismidir. Bu kısaltmaların bir başka boyutu da herhangi bir anlam ifade etmeksizin oluşmalarıdır: Aygim Ayakkabııılık, Ertaş İnşaat, MGM Kardeşler İnşaat. Bu üç iş yeri ismi dışında Süsler Pen işletmesinde de pencere kelimesinin herhangi bir dil kuralına bağlı olmaksızın kısaltıldığı ve böyle modaya ayak uydurulmaya çalışıldığı görülmektedir. Kelimenin orijinali olan pencere kullanılması daha doğru bir yol olacaktır. Hem kısaltma hem de tamlama hatası yapılarak oluşan iş yeri isimleri de mevcuttur: Foto Yilmaz, Foto Yiğit, Foto Selami, Foto Yıldırım. Fotoğrafçılık sektöründe yer alan bu dört iş yeri isimlerinin Yılmaz Fotoğrafçılık, Yiğit Fotoğrafçılık, Selami Fotoğrafçılık, Yıldırım Fotoğrafçlık olarak düzeltilmesi daha doğru olacaktır.

\section{Dil kurallarnna aykırı kullanımlarnn yer aldığı iş yeri adlarn:}

Tamlama hataları Otel Kattaş, Eczane 2000 gibi iş yeri adlarında da dikkat çekmektedir. Kattaş Otel / Oteli, 2000 Eczane / Eczanesi şeklinde isimler vermek daha uygun olacaktır. Herhangi bir nedene bağlı olmaksızın sadece yabancı bir marka imajı vermek amacıyla oluşan iş yeri adları de bulunmaktadır: $B a$ zaar Giyim, Makkas Kuaför Salonu, ÇaЯ Işı Giyim. Bu üç iş yeri ismi de Türkçenin dil kurallarına uymamaktadır. Bazaar yerine Pazar, Makkas yerine Makas, 
Çarşı yerine ÇaЯşı kelimeleri kullanılmalıdır. Group kelimesinin de bir marka imajı verilerek dikkati çekme amacıyla iş yeri isimlerinde yer aldığ görülmektedir. En azından kelime Türkçeleştirilmiş hâli olan grup olarak değiştirilerek kullanılması daha uygun olacaktır. Yapılan bu çalışmayı Atatürk'ün şu cümleleriyle sonuçlandırmak en iyi analiz olacaktır:

“Türk milletinin dili Türkçedir. Türk dili dünyada en güzel, en zengin ve en kolay olabilecek bir dildir. Onun için her Türk, dilini çok sever ve onu yükseltmek için çalışır. Bir de Türk dili Türk milleti için kutsal bir hazinedir. Çünkü Türk milleti geçirdiği nihayetsiz felaketler içinde ahlakının, ananelerinin, hatıralarının, menfaatlerinin, kısacası bugün kendi milliyetini yapan her şeyin dili sayesinde muhafaza olduğunu görüyor. Türk dili Türk milletinin kalbidir, zihnidir. Öyle istiyorum ki, Türk dili bilim yöntemleriyle kurallarını ortaya koysun ve her dalda yazı yazanlar bütün terimleriyle çoğunluğun anlatabileceği güzel, ahenkli dilimizi kullansınlar" (İnan, 1966, s.90). 


\section{EXTENDED ABSTRACT}

\section{Analysis Of Workplace Names On Language - Culture: 'Example Of Develi District' \\ Melike Somuncu \\ Siirt University}

Language is an instrument that provides agreement, and it has an important position in expressing the feelings and thoughts of the people on earth. Society exists with language and reflects culture. Within the framework of this reflection, the names given to the workplaces also have an important position. The tendency to name businesses in a foreign language has been a new trend that has affected business owners. Variables that cannot be controlled under social structure are effective in the emergence of this trend. This study consists of three parts. In the first part, the relationship between language and culture is examined. In the second part, the effects of workplace names on language are mentioned. In addition, studies related to workplace names made up to now have been mentioned and the common point of these studies has been mentioned. In the third part, the way in which the business owners in Develi, a small district, gave their names to their workplaces, was examined by the compilation method. The names of the workplaces examined are dealt with in the context of both language and culture. In the study, it was analyzed on the language and culture ground whether the causes of language pollution reflected on the names of Develi workplaces. Systematically, language is a system of indicators, and each field in the system has an area where the indicator points to the outside world. There is an outside world reality for language, and this field of reference is related to culture. The most important reason for the transfer of values from generation to generation is that human beings need a national culture in order to continue their journey of existence as a nation in the search for identity. Changing lifestyles are settled in the culture, and therefore there are some changes in the language. Change in language appears as usages that are far from the rules and structure of Turkish, and sometimes against the Turkish language. This is the most striking feature of workplace names in the context of language and culture. There are many indications that language consciousness does not exist in social life. One of 
these indicators is the names given to the workplaces. The name given to the workplaces are the language indicators chosen by the business owner for special reasons and aiming to deliver the most messages to the buyer in the shortest way. Since the business owner in the names given to the workplaces has to take into account the cultural structure of the audience, the names given to the workplace become one of the important indicators reflecting the culture of the society. The uncontrollable variables specific to the social structure are effective in the emergence of this trend. It is the intentional fashion confusion that enters our culture with technology. The absence of names throughout the workplace in recent years, Turkey is composed of words borrowed from foreign languages to a remote settlement reveals the mother tongue. Interesting, short, memorable names other than their surnames are preferred because of concerns such as being able to sell better and making businesses more interesting, while the workplaces were given the name or surname of more business owners. It is seen that the problem of entering Arabic and Persian grammar structures into Turkish for a period continues in English today. It is an area that needs to be questioned or corrected if the material or spiritual interest increases corruption in the language. If it is not questioned or corrected, a lifestyle away from language and culture is an inevitable end. The influence of foreign languages seen in the names of the workplaces, which are a kind of communication tool between the consumer and the producer / seller, has become limitless. The aim of this study is to evaluate the devotion of foreigners and foreign languages coming from globalization by Develi, which is a small district, in the workplace names and to analyze this evaluation in terms of language and culture. The name of the business owner is given to 17 business places. 48 workplaces have been given the surname of the business owner. 11 workplaces are named after the relatives of the business owner.14 workplaces were named as the hometown of the business owner. 12 businesses have been named because of the location of the business. 37 workplaces have been named because of the desire of the business to be remarkable. 10 workplaces have been named because of the business owners' desire to keep up with fashion. 21 workplaces have been named by the business owner without reason. 2 workplaces have been named because of people who are known by the business owner. 5 workplaces were made up by the owner and named after the abbreviation method. 2 workplaces have been named because of the people with whom the business owner has a close relationship. The names 
given to the workplaces due to the name, surname, nickname, relative name, country name, and the location of the business are outside the language context of our study. This is a natural situation for Develi district, which has a small and closed society, as these names are the names given to the businesses by sticking to the tradition and tradition of the business owners. This situation also shows a society that is dependent on its tradition and it is pleasing that it is not affected by the causes of language corruption, such as technology, mass media, and the ambition of foreigners and foreign culture / language. The names of the workplace of this district, where Turkish words are also frequently included, also attract attention, keep up with fashion or abbreviations without reason.

\section{Kaynakça / References}

(2002). Kültürün $A B C^{\prime}$ si. (2. baskı), İstanbul: Yapı Kredi Yayınları.

Akalın, L. S. (2002). Türkçesiz Türkçe: İstanbul tabelâları. Türk Dili Dil ve Edebiyat Dergisi, 2002/I (601), 48-54.

Akarsu, B. (1998). Dil-Kültür bağlantısı. İstanbul: İnkılap Yayınevi.

Aksan, D. (2009). Her yönüyle dil ana çizgileriyle dilbilim. Ankara: TDK Yayınları.

Aksel, M. (1976). İstanbul dükkânlarının tabela ve ilanları.Türk Folklor Araştırmaları, 17(326), 7765-7767.

Alkibay, S. (1996). Mağazalarda yabancı işletme adı kullanımına yönelik bir araştırma. Türk Dili, 538, 415-422.

Apak, H. (2014). Suriyeli Göçmenlerin kente uyumları: Mardin örneği [Elektronik Versiyonu]. Mardin Artuklu Üniversitesi: Mukaddime, 5(2), 53-70.

Arslan, A. ve Diyapoğlu, E. (2018), Ağrı İli Cumhuriyet Caddesi'ndeki iş yeri adlarının dil/kültür ilişkisi bağlamında değerlendirilmesi. Uluslararası Türkçe Edebiyat Kültür Eğitim Dergisi, 7(3), 2039-2058

Arvas A. (2011). İşyeri isimleri üzerine bir araştırma: Van örneği. Akademik Bakış, 23, 1-8.

Asutay, H. (2007). Dil, kültür ve eğitim. Konya: Eğitim Kitabevi Yayınları.

Baydar, E.(2005). Bu kadarı da fazla: Erzincan tabelaları. Türk Dili Dil ve Edebiyat Dergisi, 89(640), 359-362.

Boyraz, Ş. (2003). İletişim açısından Sivas'ta ticarî işletme adları. Millî Folklor, 15(60), 141-160.

Börekçi, M. (1993). Dil kültür bağlantısı açısından Erzurum Cumhuriyet Caddesindeki tabelalar. Yedi İklim Sanat Kültür Edebiyat Dergisi, 41, 130-132. 
Demircan, Ö. (2001). İş yeri adlarında yabancılaşma. XIV. Dilbilim Kurultayı Bildirileri. Adana: Ç.Ü. Basımevi: 4-12.

Devrim, H. (2004). Popüler kültür ve dil soruşturması. Bilim ve Aklın Aydınlığında Ĕ̆itim, 57, 130-133.

Gaddar, Z. (2014). Ödemiş ${ }^{e}$ in iş yeri adları üzerine bir inceleme. Çankırı Karatekin Üniversitesi Sosyal Bilimler Enstitüsü Dergisi, 5(1), 319-332

Göçer, A. (2012). Dil-Kültür İlişkisi ve Etkileşimi Üzerine. Türk Dili Dergisi, 729, 5056.

Gökalp, Z. (1975). Türkçülüğün esasları. İstanbul: Sebil Matbaacılık.

Güleryüz, H. (2004). Dil kirlenmesinin bir başka boyutu: İş yeri adları. Bilim ve Aklın Aydınlı̆̆ında Ĕ̆itim, 57, 121-129.

Gülsevin, G. (2006). Dil kirliliği sorunu:Türkçede yabancı unsurlar sorunu. Gülsevin, G. ve Boz, E. (Ed.). Türkçenin çă̆daş sorunları. Ankara: Gazi Kitapevi.

Güvenç, B. (1994). Insan ve kültür (6. bask1), İstanbul: Remzi Kitabevi.

İnan, A. (1966). Milliyetin temeli olan dil birliği. Türk Dili Dergisi, 182, 90.

Kandemir, E. (2014). Denizli'deki iş yeri adları üzerine bir inceleme. Yayınlanmamış Yüksek Lisans Tezi, Denizli: Pamukkale Üniversitesi Türk Dili ve Edebiyatı Ana Bilim Dalı.

Karademir, F. (2004). Diyarbakır'daki mağaza ve iş yeri adları üzerine. V. Uluslararası Türk Dili Kurultayı Bildirileri I (s. 1577-1590). Ankara.

Kartallıoğlu, Y. (2001). Trabzon Maraş Caddesindeki iş yeri isimleri üzerine. Trabzon ve Çevresi Uluslar Arası Tarih Dil Edebiyat Sempozyumu (Trabzon, 03-05 Mayıs 2001).

Kaya, D. (2008). Sivas'ta İşyeri adlandırmaları ile ilgili bazı tespitler. Uluslararası Ahilik Kültürü ve Kırşehir Sempozyumunda sunulan sözlü bildiri (Kırşehir, 1517 Ekim 2008).

Korkmaz, Z. (1997). Günümüzde dil yozlaşması. Türk Dili Dil ve Edebiyat Dergisi, 542, 129-138.

Köktekin, K. ve Kara, F. (2006). Erzurum iş yeri adlarında dil kirliliği. Türk Dili Dil ve Edebiyat Dergisi, 660, 519-523.

Kubbealtı Akademesi. (t.y). Kubbealtı lugatı.http://lugatim.com/ adresinden erişilmiştir. Küçük, S. (2007). Dil Kirliliğinin Türkçemize Yansımaları. Türk Dili Dil ve Edebiyat Dergisi, XCIV(669), 504-514.

Küçük, S. ve Serdar, S. (2008). İş yeri adlarındaki batı kaynaklı kelimeler ve Ordu İli Örneği. Türk Dili ve Edebiyatı Dergisi, 38, 137-155.

Mert, K. (2009). Mizah algısının pazarlamada bıraktığı tebessüm işyeri isimlerinin içerik analizi. 15.Ulusal Pazarlama Kongresi, Dokuz Eylül Üniversitesi. 
Mert, K. ve M. Türkmen (2014). Türkçe biz sana ne yaptık böyle? İş yeri isimleri yabancilaşıyor: Türkiye'nin kültürel değişim yolculuğu. 12. Uluslararası Bilgi, Ekonomi ve Yönetim Kongresi Bildirileri: 599-607.

Özkan, F., ve Musa, B. (2004). Yabancı dillerin Türkçenin söz dizimi üzerindeki etkisi. Bilig Dergisi, 30, 95-139.

Sancak, Ş. vd. (2008). Dil ve kültür yozlaşmasında Giresun örneklemi. Karadeniz Araştırmaları, 16, 101-111.

Soğanc1, E. (2000). Bir markanın oluşumda görsel kimliğin etkisi. Süleyman Demirel Üniversitesi Güzel Sanatlar Fakültesi Grafik Bölümü.

Somuncu, A. Ş. (2018). Develi İlçesi esnaf dili. Erciyes Üniversitesi Sosyal Bilimler Enstitüsü, Basılmamış Yüksek Lisans Tezi, Kayseri.

Şanll, C. (1999), Edirne'de iş yeri isimleri üzerine bir araştırma. Türk Dili, 567(3), 191-194.

Şeyda, A. (2005). Dil açısından Kars'taki iş yeri isimleri. Atatürk Üniversitesi Kazım Karabekir Eğitim Fakültesi Dergisi, 12, 77-88.

Turan, O. (1980). Tarihî akış içinde din ve medeniyet. İstanbul: Nakışlar Yayınevi.

Üstünova, K. (1996). Bursa'da tabelâ adları. Türk Dili Dil ve Edebiyat Dergisi. 533, 1186-1190.

Üstünova, M. vd. (2010). İş yeri adlarında Türkçenin kullanımı. Turkish Studies, International Periodical For The Languages, Literature and History of Turkish or Turkic. 5(1), 1390-1419.

Yaman, I., ve Ekmekçi, E. (2016). Türkçenin İngilizce yoluyla melezleşmesi: Samsun'daki iş yeri ve mekân adları örneği. Karadeniz Araştırmaları, 50, 217-229.

Yıldız, T. (2014). Saussure'den Bakthin'e dil-kültür ilişkisi: Tümü kapsayıcı olgu. İdil, 3(11), 115-136.

Zengin, E. (2017). Türkçenin diğer dillerle etkileşimi ve sonuçları. Uluslararası Sosyal Araștırmalar Dergisi, 10(52), 293-299.

\section{Kisaltmalar}

Ar.: Arapça

Çin.: Çince

Far.: Farsça

Fran.: Fransizca

İt.: İtalyanca

öz. is.: özel isim

Por.: Portekizce

T.: Türkçe 
Kaynakça Bilgisi / Citation Information

Somuncu, M. (2020). İş yeri adlarının dil- kültür zemininde incelenmesi: Develi İlçesi örneği. OPUS-Uluslararası Toplum Araştırmaları Dergisi, 16(29), 1955-1986. DOI: 10.26466/opus.703795 